\title{
Methionine improves the performance and breast muscle growth of broilers with lower hatching weight by altering the expression of genes associated with the insulin-like growth factor-I signalling pathway
}

\author{
Chao Wen, Ping Wu, Yueping Chen, Tian Wang* and Yanmin Zhou* \\ College of Animal Science and Technology, Nanjing Agricultural University, No. 1 Weigang, Nanjing, Jiangsu 210095, \\ People's Republic of China
}

(Submitted 18 January 2013 - Final revision received 24 June 2013 - Accepted 25 June 2013 - First published online 6 August 2013)

\section{Abstract}

The present study aimed to investigate the responses of broilers with different hatching weights (HW) to dietary methionine (Met). A total of 192 1-d-old Arbor Acres broiler chicks with different HW (heavy: $48 \cdot 3$ (SEM 0.1) g and light: $41 \cdot 7$ (SEM 0.1) g) were allocated to a $2(\mathrm{HW}) \times 2$ (Met) factorial arrangement with six replicates of eight chicks. Control starter $(1-21 \mathrm{~d})$ and finisher $(22-42 \mathrm{~d})$ diets contained 0.50 and $0.43 \%$ Met, respectively. Corresponding values for a high-Met treatment were 0.60 and $0.53 \%$. Light chicks had poorer $(P<0.05)$ growth performance and breast muscle weight and lower $(P<0.05)$ insulin-like growth factor-I (IGF-I) concentration and mRNA level in breast muscle than heavy chicks when both were fed the control diets. High-Met diets improved performance and promoted breast muscle growth and IGF-I concentration in light chicks $(P<0 \cdot 05)$. Increased $I G F-I$ and target of rapamycin $(T O R)$ mRNA levels as well as decreased eIF4E-binding protein 1 (4EBP1), atrogin-1 and forkhead box O 4 (FOXO4) mRNA levels were induced by high-Met diets in light chicks $(P<0 \cdot 05)$. In conclusion, the Met requirement of broilers might depend on their HW and Met levels used in the control diets in the present study were adequate for heavy chicks but inadequate for light chicks, resulting in poorer performance and breast muscle growth, which were improved by increasing dietary Met supply presumably through alterations in IGF-I synthesis and gene expression of the TOR/4EBP1 and FOXO4/atrogin-1 pathway.

Key words: Methionine: Broilers: Hatching weights: Breast muscle: Insulin-like growth factor-I

Methionine (Met) is the first limiting amino acid in chicken diets. Dietary Met deficiency has been demonstrated to impair chicken growth ${ }^{(1)}$; thus, it is important to have accurate information on Met requirement of chicks for formulating diets to optimise their growth and production. The requirement of Met for growth and maintenance would be expected to vary with factors that influence maximum growth and feed intake $^{(2)}$. Extensive work has been carried out to estimate the Met requirement of broilers under various conditions such as sex, dietary nutrients and rearing environment ${ }^{(2-4)}$. However, none of such studies has taken the hatching weight (HW) of broiler chicks into consideration. In fact, the performance of broiler chicks is largely influenced by $\mathrm{HW}^{(5-7)}$. The average HW may vary largely from 36 to $48 \mathrm{~g}$, depending on egg weight and hatching process ${ }^{(8)}$. Sklan et al. ${ }^{(9)}$ reported that the marketing weight was about $1 \cdot 1$-fold higher in broilers hatching at 53.1 (SEM 0.5$) \mathrm{g}$ than in those hatching at 43.5 (SEM 0.5) $\mathrm{g}$ and suggested that this growth process was regulated by skeletal muscle growth. It has been proven that muscle growth is stimulated by the insulin-like growth factor-I (IGF-I) signalling pathway ${ }^{(10,11)}$, which is activated by amino acids, especially $\mathrm{Met}^{(12)}$. Met deficiency has been shown to result in lower breast muscle weight in broilers ${ }^{(1)}$, and a positive effect of increasing dietary Met levels on chicken breast muscle yield has also been reported ${ }^{(13)}$. Whether high-Met diets can improve the performance and muscle growth of broilers with lower HW is unknown. However, to our knowledge, the responses of chicks with different HW to dietary Met have not been reported.

Skeletal muscle hypertrophy in response to IGF-I is critically mediated by the serine/threonine kinase Akt, the downstream targets of which include target of rapamycin (TOR), eIF4Ebinding protein 1 (4EBP1) and ribosomal protein $\mathrm{S} 6$ kinase 1 (S6K1), key regulators involved in mRNA translation and protein synthesis $^{(14)}$. IGF-I has also been shown to prevent the expression of muscle atrophy-induced ubiquitin ligases,

Abbreviations: 4EBP1, eIF4E-binding protein 1; FOXO, forkhead box O; HW, hatching weight; IGF-I, insulin-like growth factor-I; Met, methionine; S6K1, ribosomal protein S6 kinase 1; TOR, target of rapamycin.

*Corresponding authors: Y. Zhou, fax +8625 84395314, email zhouym6308@163.com; T. Wang, email tianwang@njau.edu.cn 
atrogin-1 and muscle ring finger-1 (MuRF1), by inhibiting the forkhead box $\mathrm{O}$ (FOXO) subfamily of transcription factors $^{(15,16)}$, which consists of four members, FOXO1, FOXO3, FOXO4 and FOXO6 ${ }^{(17)}$. Daily variations in dietary lysine content alter TOR and FOXO phosphorylation and atrogin-1 mRNA expression in chicken pectoralis major muscle ${ }^{(18)}$. However, little information is available on the response of these pathways to dietary Met in chickens.

The objective of the present study was to evaluate the effects of dietary Met on the performance, breast muscle growth and expression of genes associated with the IGF-I signalling pathway in broilers with different HW.

\section{Materials and methods}

\section{Bird husbandry, diets and experimental design}

All experimental procedures involving animals were approved by the Nanjing Agricultural University Institutional Animal Care and Use Committee.

A $42 \mathrm{~d}$ feeding trial was conducted with 192 1-d-old Arbor Acres broiler chicks with different HW (heavy: $48 \cdot 3$ (SEm 0.1)g and light: $41.7(\operatorname{SEM~} 0 \cdot 1) \mathrm{g}$ ) from the same maternal flock ( 47 weeks of age). They were allocated to a randomised block design with a $2(\mathrm{HW}) \times 2$ (Met) factorial arrangement with six replicates of eight chicks (half males and half females) per replicate cage $(110 \mathrm{~cm} \times 60 \mathrm{~cm} \times 50 \mathrm{~cm})$. Control starter $(1-21 \mathrm{~d})$ and finisher $(22-42 \mathrm{~d})$ diets were formulated to contain 0.50 and $0.43 \%$ Met, respectively, according to the NRC (1994) requirements for broilers (Table 1). A high-Met treatment was formulated by adding 0.1\% DL-Met ( $98 \%$; Adisseo, Inc.) on top of the control diets ( 0.60 and $0.53 \%$ Met during the starter and finisher phases, respectively). Chicks were allowed free access to mash feed and water in three-layered battery cage units in a temperature-controlled room. Continuous light was maintained, and the temperature of the experimental room was set at $32-34^{\circ} \mathrm{C}$ for the first $3 \mathrm{~d}$ and then reduced by $2-3^{\circ} \mathrm{C}$ per week to a final temperature of $20^{\circ} \mathrm{C}$. At $42 \mathrm{~d}$ of age, chicks were weighed and feed consumption was recorded by replicate to calculate body weight, average daily gain, average daily feed intake and feed conversion ratio (feed intake:weight gain). Mortality was also recorded. Chicks that died during the experiment were weighed, and data were included only in the calculation of feed conversion ratio.

\section{Sample collection}

At $42 \mathrm{~d}$ of age, one chick from each replicate was randomly selected and weighed after feed deprivation for $12 \mathrm{~h}$. Chicks were killed by cervical dislocation. The whole breast (including pectoralis major and minor) muscle was weighed, and then samples were collected from the pectoralis major muscle and stored in liquid $\mathrm{N}_{2}$ until analysis.

\section{Measurement of insulin-like growth factor-I levels in breast muscle}

After thawing at room temperature, the breast muscle samples were homogenised $(1: 19, \mathrm{w} / \mathrm{v})$ with an ice-cold physiological
Table 1. Composition and nutrient content of basal diets (as-fed basis)

\begin{tabular}{|c|c|c|}
\hline Items & $1-21 d$ & $22-42 d$ \\
\hline \multicolumn{3}{|l|}{ Ingredients (\%) } \\
\hline Maize & $57 \cdot 0$ & 61.9 \\
\hline Soyabean meal & $31 \cdot 3$ & $25 \cdot 6$ \\
\hline Maize gluten meal & 3.9 & $4 \cdot 3$ \\
\hline Soyabean oil & $3 \cdot 1$ & 3.8 \\
\hline Dicalcium phosphate & 1.8 & 1.6 \\
\hline Limestone & 1.3 & 1.2 \\
\hline L-Lys, $\mathrm{HCl}$ & 0.15 & 0.2 \\
\hline DL-Met & 0.15 & 0.1 \\
\hline $\mathrm{NaCl}$ & 0.3 & 0.3 \\
\hline Vitamin and mineral $\mathrm{mix}^{*}$ & 1.0 & 1.0 \\
\hline \multicolumn{3}{|l|}{ Calculated nutrient content } \\
\hline Metabolisable energy (MJ/kg) & $12 \cdot 69$ & $13 \cdot 10$ \\
\hline $\mathrm{CP}(\%)$ & 21.52 & $19 \cdot 71$ \\
\hline Lys (\%) & 1.14 & 1.04 \\
\hline Met (\%) & 0.50 & 0.43 \\
\hline Total sulphur amino acids (\%) & 0.85 & 0.76 \\
\hline $\mathrm{Ca}(\%)$ & 1.00 & 0.90 \\
\hline Available P (\%) & 0.46 & 0.42 \\
\hline \multicolumn{3}{|l|}{ Analysed nutrient content } \\
\hline $\mathrm{CP}(\%)$ & 21.76 & $19 \cdot 23$ \\
\hline Lys (\%) & $1 \cdot 18$ & 1.02 \\
\hline Met (\%) & 0.51 & 0.40 \\
\hline Total sulphur amino acids (\%) & 0.89 & 0.73 \\
\hline Arg & 1.32 & $1 \cdot 21$ \\
\hline Thr & 0.82 & 0.78 \\
\hline Val & 1.03 & 0.90 \\
\hline \multicolumn{3}{|c|}{ 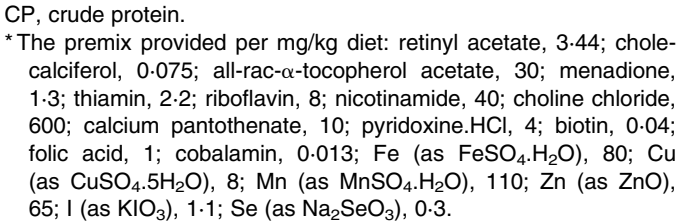 } \\
\hline
\end{tabular}

saline solution and then centrifuged at $5000 \mathrm{~g}$ for $10 \mathrm{~min}$ at $4^{\circ} \mathrm{C}$. Aliquots of the supernatant were collected for subsequent assay. All determinations were carried out in duplicate. Total protein content was determined as described previously ${ }^{(19)}$. The concentration of IGF-I was measured using a commercial chicken-specific ELISA kit (Nanjing Jiancheng Bioengineering Institute), and it is expressed as $\mathrm{ng} / \mathrm{mg}$ protein.

\section{mRNA quantification}

Total RNA was isolated from breast muscle as described previously $^{(20)}$, using RNAiso reagent (TaKaRa Biotechnology). Its purity and concentration were measured using a NanoDrop ND-1000 UV spectrophotometer (NanoDrop Technologies). Later, RNA samples were diluted in diethyl pyrocarbonatetreated water to an appropriate concentration.

Reverse transcription of total RNA was carried out using a PrimeScript RT reagent Kit (TaKaRa). The geometric means of glyceraldehyde-3-phosphate dehydrogenase (GAPDH) and $\beta$-actin were used to normalise the genes of interest as recommended $^{(21)}$. The primers for IGF-I, $\beta$-actin and $G A P D H$ were synthesised according to the method of $\mathrm{Li}$ et $a l .{ }^{(22)}$, Kogut et $a l .{ }^{(23)}$ and Wang et al. ${ }^{(24)}$, respectively, and those for TOR, 4EBP1, S6K1, atrogin-1, MuRF1, FOXO1 and FOXO4 were specifically designed according to the 
Table 2. Sequences used for real-time PCR primers

\begin{tabular}{|c|c|c|c|}
\hline Genes & GeneBank ID & Primer sequence, sense/antisense & Product size $(\mathrm{bp})$ \\
\hline IGF-I & M32791 & CATTTCTTCTACСTTGGC & 191 \\
\hline TOR & XM_417614 & $\begin{array}{l}\text { TCATCCACTATTCCCTTG } \\
\text { CCAGGATTCTTCGGACTA } \\
\text { CCATCACAAACCCTTATT }\end{array}$ & 249 \\
\hline $4 E B P 1$ & XM_424384 & $\begin{array}{l}\text { ACCAGGATTATTTATGACCG } \\
\text { TTCACCTACATTCGCTTTCT }\end{array}$ & 174 \\
\hline S6K1 & NM_001030721 & $\begin{array}{l}\text { CATGATTTCCAAACGACCAGA } \\
\text { AGTAAACCAAACAAGCCCTCC }\end{array}$ & 134 \\
\hline Atrogin-1 & NM_001030956 & $\begin{array}{l}\text { ACTTTGGTTCAACGGGTCG } \\
\text { CGGTCTTCGCTGAGCACTT }\end{array}$ & 254 \\
\hline MuRF1 & XM_424369 & $\begin{array}{l}\text { GGATGCCTTCACAGTCAGTC } \\
\text { TGCGGAATAGTCCTCTTGG }\end{array}$ & 254 \\
\hline FOXO1 & NM_204328 & $\begin{array}{l}\text { ATGCGACCTCTGGTAATA } \\
\text { AAGTGTAGGCAAATCGTC }\end{array}$ & 307 \\
\hline FOXO4 & XM_426261 & $\begin{array}{l}\text { CTCGCTAAGGTCAGAAGTAAA } \\
\text { TCCTCAGTCACGGTTGGT }\end{array}$ & 302 \\
\hline$\beta$-Actin & NM_205518 & $\begin{array}{l}\text { TGCTGTGTTCCCATCTATCG } \\
\text { TTGGTGACAATACCGTGTTCA }\end{array}$ & 150 \\
\hline$G A P D H$ & NM_204305 & $\begin{array}{l}\text { AGAACATCATCCCAGCGTCC } \\
\text { CGGCAGGTCAGGTCAACAAC }\end{array}$ & 133 \\
\hline
\end{tabular}

IGF-I, insulin-like growth factor-I; TOR, target of rapamycin; 4EBP1, elF4E-binding protein 1; S6K1, ribosomal protein S6 kinase 1; MuRF1, muscle ring finger-1; FOXO, forkhead box O; GAPDH, glyceraldehyde-3phosphate dehydrogenase.

sequences in GenBank (Table 2). Quantification of mRNA was performed on an ABI 7300 Real-Time PCR System (Applied Biosystems) using SYBR Premix Ex Taq II (TaKaRa). Optimised cycling conditions for all the genes were $95^{\circ} \mathrm{C}$ for $30 \mathrm{~s}$ followed by forty cycles of $95^{\circ} \mathrm{C}$ for $5 \mathrm{~s}$ and $60^{\circ} \mathrm{C}$ for $31 \mathrm{~s}$ and a final dissociation stage of $95^{\circ} \mathrm{C}$ for $15 \mathrm{~s}, 60^{\circ} \mathrm{C}$ for $1 \mathrm{~min}$, $95^{\circ} \mathrm{C}$ for $15 \mathrm{~s}$ and $60^{\circ} \mathrm{C}$ for $15 \mathrm{~s}$. All measurements were carried out in triplicate, and average values were obtained. Relative mRNA levels (arbitrary units) were calculated on the basis of PCR efficiency and threshold cycle $\left(C_{\mathrm{t}}\right)$ values as described previously ${ }^{(25)}$. The mRNA level of each target gene in heavy chicks fed the control diets was assigned a value of 1 .

\section{Statistical analysis}

Two-way ANOVA was employed to determine the main effects of HW and Met and their interaction using the general linear model procedure of SPSS software (version 16.0; SPSS, Inc.). Differences among the treatments were examined by oneway ANOVA using Duncan's multiple range test, which were considered significant at $P<0.05$, and $P$ values between 0.05 and $0 \cdot 1$ were considered as a trend. Data are presented as means with their pooled standard errors.

\section{Results}

\section{Growth performance}

Mortality was low (3\%) and not related to treatment (data not shown). Heavy chicks had higher $(P<0.05) 42 \mathrm{~d}$ body weight and average daily gain than light chicks when both were fed the control diets, and feed conversion ratio showed a decreasing trend $(P=0.094)$ (Table 3$)$. High-Met diets improved $(P<0.05) 42 \mathrm{~d}$ body weight, average daily gain and feed conversion ratio in light chicks but not in heavy chicks $(\mathrm{HW} \times$ Met interaction; $P<0.05)$. The performance of light chicks fed high-Met diets was similar to that of heavy chicks fed either diet. There was no difference in average daily feed intake among the groups.

\section{Breast muscle weight and insulin-like growth factor-I concentration}

The absolute weight of breast muscle and concentration of IGF-I were lower $(P<0 \cdot 05)$ in light chicks than in heavy chicks when both were fed the control diets, and the same trend was

Table 3. Effect of methionine (Met) levels on the performance of broilers with different hatching weights (HW) from 1 to $42 \mathrm{~d}$ of age

(Mean values with their standard errors, $n 6,8$ chicks per replicate)

\begin{tabular}{|c|c|c|c|c|c|}
\hline $\mathrm{HW}$ & Met & $\begin{array}{c}42 \mathrm{~d} B W \\
\text { (g) }\end{array}$ & $\begin{array}{l}\text { ADG } \\
(g / d)\end{array}$ & $\begin{array}{l}\text { ADFI } \\
(g / d)\end{array}$ & $\mathrm{FCR}^{*}$ \\
\hline \multirow[t]{2}{*}{ Heavy† } & Control $\ddagger$ & $2368^{a}$ & $56 \cdot 6^{a}$ & $104 \cdot 2$ & $1 \cdot 85^{a, b}$ \\
\hline & High§ & $2276^{a, b}$ & $54 \cdot 3^{a, b}$ & $98 \cdot 8$ & $1 \cdot 82^{b}$ \\
\hline \multirow[t]{2}{*}{ Light $\|$} & Control & $2116^{b}$ & $50 \cdot 6^{\mathrm{b}}$ & $97 \cdot 2$ & $1.92^{\mathrm{a}}$ \\
\hline & High & $2366^{a}$ & $56 \cdot 7^{a}$ & $100 \cdot 1$ & $1.77^{b}$ \\
\hline SEM & & 33 & 0.8 & $1 \cdot 3$ & 0.02 \\
\hline \multicolumn{6}{|l|}{$P$} \\
\hline HW & & 0.227 & 0.266 & 0.294 & 0.722 \\
\hline Met & & 0.238 & 0.237 & 0.635 & 0.008 \\
\hline $\mathrm{HW} \times$ Met & & 0.016 & 0.016 & 0.126 & 0.046 \\
\hline
\end{tabular}

BW, body weight; $A D G$, average daily gain; $A D F I$, average daily feed intake; FCR, feed conversion ratio.

${ }^{\mathrm{a}, \mathrm{b}}$ Mean values within a column with unlike superscript letters were significantly different $(P<0.05)$.

${ }^{*} \mathrm{FCR}=$ feed intake:weight gain.

† Mean hatching weight of 48.3 (SEM 0.1 ) g.

$\ddagger 0.50$ and $0.43 \%$ Met during the starter (1-21d) and finisher (22-42d) phases, respectively.

$\S 0.60$ and $0.53 \%$ Met during the starter (1-21d) and finisher (22-42d) phases, respectively.

\| Mean hatching weight of 41.7 (SEM 0.1) g. 
Table 4. Effect of methionine (Met) levels on breast (including pectoralis major and minor) muscle weight and insulin-like growth factor-I (IGF-I) concentration of broilers with different hatching weights $(\mathrm{HW})$ at $42 \mathrm{~d}$ of age

(Mean values with their standard errors, $n 6,8$ chicks per replicate)

\begin{tabular}{llccc}
\hline & & \multicolumn{2}{c}{ Breast muscle weight } & \\
\cline { 3 - 4 } HW & Met & $\begin{array}{c}\text { Absolute } \\
(\mathrm{g})\end{array}$ & $\begin{array}{c}\text { Relative } \\
(\mathrm{g} / \mathrm{kg} \mathrm{BW})\end{array}$ & $\begin{array}{c}\text { IGF-I } \\
(\mathrm{ng} / \mathrm{mg} \text { protein })\end{array}$ \\
\hline Heavy ${ }^{*}$ & Control† & $431^{\mathrm{a}}$ & $186^{\mathrm{a}, \mathrm{b}}$ & $49 \cdot 5^{\mathrm{a}}$ \\
& High $\ddagger$ & $442^{\mathrm{a}}$ & $180^{\mathrm{a}, \mathrm{b}}$ & $46 \cdot 2^{\mathrm{a}, \mathrm{b}}$ \\
Light $\S$ & Control & $362^{\mathrm{b}}$ & $172^{\mathrm{b}}$ & $43 \cdot 0^{\mathrm{b}}$ \\
& High & $463^{\mathrm{a}}$ & $187^{\mathrm{a}}$ & $48 \cdot 2^{\mathrm{a}}$ \\
SEM & & 10 & 2 & 0.7 \\
P & & & & \\
HW & & 0.240 & 0.487 & 0.147 \\
Met & & 0.010 & 0.318 & 0.521 \\
HW $\times$ Met & & 0.034 & 0.042 & 0.013 \\
\hline
\end{tabular}

BW, body weight.

${ }^{a, b}$ Mean values within a column with unlike superscript letters were significantly different $(P<0.05)$.

* Mean hatching weight of 48.3 (SEM 0.1 ) g.

$\dagger 0.50$ and $0.43 \%$ Met during the starter (1-21d) and finisher (22-42d) phases, respectively.

$\ddagger 0.60$ and $0.53 \%$ Met during the starter $(1-21 \mathrm{~d})$ and finisher $(22-42 \mathrm{~d})$ phases, respectively.

$\S$ Mean hatching weight of 41.7 (SEM 0.1) g.

observed for relative weight $(P=0.067)$ (Table 4). High-Met diets increased $(P<0.05)$ the absolute and relative weights of breast muscle as well as concentration of IGF-I in light chicks but not in heavy chicks (HW $\times$ Met interaction; $P<0 \cdot 05)$.

\section{mRNA expression}

The expression of $I G F-I$ mRNA was lower $(P<0 \cdot 05)$ in light chicks than in heavy chicks when both were fed the control diets, while that of other genes tested did not differ $(P>0 \cdot 10$; Table 5). High-Met diets up-regulated $(P<0.05)$ the mRNA levels of IGF-I and TOR and down-regulated those of 4EBP1, atrogin-1 and FOXO4 in light chicks $(P<0 \cdot 05)$, but no difference was observed in heavy chicks. Treatments did not affect the expression of MuRF1, S6K1 or FOXO1 mRNA.

\section{Discussion}

The present study confirmed that heavy chicks had better performance than light ones when both were fed the control diets, as reported previously ${ }^{(7,9)}$. High-Met diets improved the performance of light chicks, which was similar to that of heavy chicks, indicating that Met levels used in the control diets in the present study were adequate for heavy chicks but inadequate for light chicks. Similar results were obtained by Leandro et $a l .{ }^{(5)}$, who reported that performance from 1 to $40 \mathrm{~d}$ of age did not differ between broilers with $\mathrm{HW}$ of $40 \cdot 4$ (SEM 0.5) and those with HW of $49 \cdot 3$ (SEM 1.1) g, when high Met amounts were included in the diets $(0.61 \%$ for $1-7 \mathrm{~d}, 0.57 \%$ for $8-21 \mathrm{~d}$ and $0.54 \%$ for $22-40 \mathrm{~d}$ ). This implied that the Met requirement of broilers might depend, at least in part, on their HW and that those with lower HW might need more Met supply to achieve their growth potential.

In the present study, light chicks fed the control diets had lower breast muscle weight at $42 \mathrm{~d}$ of age. This finding is in agreement with the results of Sklan et al. ${ }^{(9)}$. The concentration of IGF-I in the breast muscle of light chicks followed a similar pattern, which suggests that differences in breast muscle growth might be due to variations in IGF-I synthesis ${ }^{(9,26)}$. Breast muscle weight and IGF-I concentration of light chicks were promoted by high-Met diets, suggesting that Met may improve breast muscle growth by enhancing IGF-I synthesis. The improvement of breast meat yield by high-Met diets has been reported previously ${ }^{(13,27)}$. However, there is little literature on the response of breast muscle IGF-I content to Met levels in broiler diets. The response of plasma IGF-I levels to dietary Met has been reported previously ${ }^{(28)}$, but as Nagao et al. ${ }^{(29)}$ reported, the regulatory effect of dietary Met was independent of the change in plasma IGF-I concentration. The lack of response in heavy chicks could be attributed to the fact that these chicks had greater muscle mass with more satellite cells that underwent higher proliferation and earlier differentiation after hatching ${ }^{(9)}$ and thus were less sensitive to high-Met diets.

Table 5. Effect of methionine (Met) levels on the relative mRNA levels* in the breast muscle of broilers with different hatching weights $(\mathrm{HW})$ at $42 \mathrm{~d}$ of age

(Mean values with their standard errors, $n 6,8$ chicks per replicate)

\begin{tabular}{llllllllll}
\hline HW & Met & IGF-I & TOR & 4EBP1 & S6K1 & Atrogin-1 & MuRF1 & FOXO1 & FOXO4 \\
\hline Heavy $\dagger$ & Control & $1.00^{\mathrm{a}}$ & $1.00^{\mathrm{b}}$ & $1.00^{\mathrm{a}}$ & 1.00 & $1.00^{\mathrm{a}, \mathrm{b}}$ & 1.00 & 1.00 & $1.00^{\mathrm{a}, \mathrm{b}}$ \\
& High§ & $0.91^{\mathrm{a}, \mathrm{b}}$ & $0.89^{\mathrm{b}}$ & $0.85^{\mathrm{a}, \mathrm{b}}$ & 0.98 & $0.93^{\mathrm{a}, \mathrm{b}}$ & 0.89 & 0.92 & $0.88^{\mathrm{a}, \mathrm{b}}$ \\
Light $\|$ & Control & $0.66^{\mathrm{b}}$ & $0.91^{\mathrm{b}}$ & $0.99^{\mathrm{a}}$ & 1.03 & $1.13^{\mathrm{a}}$ & 1.13 & 0.99 & $1.18^{\mathrm{a}}$ \\
& High & $1.10^{\mathrm{a}}$ & $1.41^{\mathrm{a}}$ & $0.76^{\mathrm{b}}$ & 0.94 & $0.64^{\mathrm{b}}$ & 0.87 & 0.85 & $0.83^{\mathrm{b}}$ \\
SEM & & 0.05 & 0.05 & 0.04 & 0.04 & 0.06 & 0.06 & 0.06 & 0.05 \\
$P$ & & & & & & & & & \\
HW & & 0.478 & 0.062 & 0.510 & 0.963 & 0.501 & 0.696 & 0.722 & 0.529 \\
Met & & 0.114 & 0.092 & 0.019 & 0.404 & 0.030 & 0.150 & 0.370 & 0.035 \\
HWXMet & & 0.022 & 0.011 & 0.547 & 0.625 & 0.091 & 0.532 & 0.784 & 0.293 \\
\hline
\end{tabular}

IGF-I, insulin-like growth factor-I; TOR, target of rapamycin; 4EBP1, elF4E-binding protein 1; S6K1, ribosomal protein S6 kinase 1; MuRF1, muscle ring finger-1; FOXO, forkhead box $O$.

a,b Mean values within a column with unlike superscript letters were significantly different $(P<0.05)$.

* The mRNA level of each target gene in heavy chicks fed the control diets was assigned a value of 1 (arbitrary units).

† Mean hatching weight of $48 \cdot 3$ (SEM 0.1$) \mathrm{g}$.

$\ddagger 0.50$ and $0.43 \%$ Met during the starter $(1-21 \mathrm{~d})$ and finisher (22-42 d) phases, respectively

$\S 0.60$ and $0.53 \%$ Met during the starter $(1-21 \mathrm{~d})$ and finisher $(22-42 \mathrm{~d})$ phases, respectively.

II Mean hatching weight of 41.7 (SEM 0.1$) \mathrm{g}$. 
As a first step in the elucidation of the mechanism by which breast muscle growth is regulated by Met, the mRNA levels of genes related to the IGF-I signalling pathway were measured in the present study. The levels of $I G F-I$ mRNA in breast muscle were lower in light chicks than in heavy ones when both were fed the control diets, supporting the hypothesis that IGF-I mRNA may participate in the setting of muscle growth rate during development ${ }^{(26)}$. High-Met diets increased $I G F-I$ mRNA levels in light chicks, which was parallel to the changes in its concentration. Nutrient supply has been reported to enhance the expression of IGF-I mRNA in chicken skeletal muscle ${ }^{(22,30)}$, but no data are available on its response to dietary Met. Increased TOR and decreased $4 E B P 1 \mathrm{mRNA}$ levels without any change in the expression of $S 6 K 1 \mathrm{mRNA}$ in light chicks fed high-Met diets imply that the TOR/4EBP1 pathway may be regulated by Met at the transcriptional level. Further work is required to determine whether the phosphorylation of these proteins is involved in this process. The present findings are not consistent with those of Wang et $a l .{ }^{(24)}$, who reported that decreasing dietary nutrient density increased the levels of TOR, $4 E B P 1$ and S6K1 mRNA in the gastrocnemius muscle but not in the pectoralis major muscle of slow-growing chickens. This discrepancy may be related to broiler strains and muscle types. The reduction in the expression of atrogin-1 mRNA without any change in that of MURF1 in the breast muscle of light chicks fed high-Met diets indicates that Met may improve the muscle growth of light chicks by preventing the down-regulation of protein synthesis but not proteolysis ${ }^{(31)}$. Met supply has been reported to modulate the expression of atrogin-1 in quail muscle fibroblasts $^{(32)}$. In other studies, the expression of atrogin-1 mRNA has been reported to be increased in chickens fed low-lysine diets ${ }^{(18)}$ or subjected to fasting ${ }^{(33)}$, showing that the expression of atrogin-1 is affected by nutritional status. A change in FOXO4 mRNA expression that was the same as that in atrogin-1 mRNA expression suggests that Met may regulate the expression of atrogin-1 by inhibiting FOXO4, which is probably induced by the enhanced expression of $I G F-I$ and associated signalling pathway ${ }^{(15)}$. Parallel changes in the expression of atrogin-1 and FOXO4 mRNA have been observed in growing rats fed diets with different amino acid profiles $^{(34)}$. Previous research has shown the regulatory effect of FOXO4 on the expression of atrogin-1 ${ }^{\text {(35) }}$. No difference in the expression of FOXO1 mRNA suggests that the response to dietary Met is isoform specific, with FOXO4 being more sensitive. This may be explained by the differential expression level of these isoforms between different organs; for example, FOXO4 is highly expressed in muscle, whereas FOXO1 is highly expressed in adipose tissue ${ }^{(17)}$

In conclusion, Met levels used in the control diets in the present study were adequate for heavy chicks but inadequate for light chicks, resulting in poorer performance and breast muscle growth, which were improved by increasing dietary Met supply probably through alterations in IGF-I synthesis and gene expression of the TOR/4EBP1 and FOXO4/atrogin-1 pathway.

\section{Acknowledgements}

The authors thank their laboratory colleagues for their assistance.

The authors acknowledge Anhui Hewei Agricultural Development Company Limited (Guangde, Xuancheng, Anhui, China) for providing the chicks without charge. The company had no role in the design, analysis or writing of the article.

The contributions of the authors are as follows: P. W. and Y. C. carried out the experiments together with C. W., who also performed the data analysis and wrote the manuscript; Y. Z. and T. W. designed and supervised the study and revised the manuscript.

The authors had no conflicts of interest.

\section{References}

1. Corzo A, Kidd M, Dozier W, et al. (2006) Protein expression of pectoralis major muscle in chickens in response to dietary methionine status. Br J Nutr 95, 703-708.

2. Chamruspollert M, Pesti GM \& Bakalli RI (2002) Determination of the methionine requirement of male and female broiler chicks using an indirect amino acid oxidation method. Poult Sci 81, 1004-1013.

3. Chamruspollert M, Pesti GM \& Bakalli RI (2002) Dietary interrelationships among arginine, methionine, and lysine in young broiler chicks. Br J Nutr 88, 655-660.

4. Chamruspollert M, Pesti GM \& Bakalli RI (2004) Influence of temperature on the arginine and methionine requirements of young broiler chicks. J Appl Poult Res 13, 628-638.

5. Leandro NSM, Cunha WCP, Stringhini JH, et al. (2006) Effect of broiler chicken initial weight on performance, carcass yield and economic viability. Rev Bras Zootec 35, 2314-2321.

6. Willemsen H, Everaert N, Witters A, et al. (2008) Critical assessment of chick quality measurements as an indicator of posthatch performance. Poult Sci 87, 2358-2366.

7. Mendes A, Paixão S, Restelatto R, et al. (2011) Effects of initial body weight and litter material on broiler production. Rev Bras Ciênc Avic 13, 165-170.

8. Shalev BA \& Pasternak H (1995) Incremental changes in and distribution of chick weight with hen age in four poultry species. Br Poult Sci 36, 415-424.

9. Sklan D, Heifetz S \& Halevy O (2003) Heavier chicks at hatch improves marketing body weight by enhancing skeletal muscle growth. Poult Sci 82, 1778-1786.

10. McMurtry JP (1998) Nutritional and developmental roles of insulin-like growth factors in poultry. J Nutr 128, 302S-305S.

11. Beccavin C, Chevalier B, Cogburn L, et al. (2001) Insulin-like growth factors and body growth in chickens divergently selected for high or low growth rate. J Endocrinol 168, 297-236

12. Dozier WA, Kidd MT \& Corzo A (2008) Dietary amino acid responses of broiler chickens. J Appl Poult Res 17, 157-167.

13. Hickling D, Guenter W \& Jackson ME (1990) The effects of dietary methionine and lysine on broiler chicken performance and breast meat yield. Can J Anim Sci 70, 673-678.

14. Bodine SC, Stitt TN, Gonzalez M, et al. (2001) Akt/mTOR pathway is a crucial regulator of skeletal muscle hypertrophy and can prevent muscle atrophy in vivo. Nat Cell Biol 3, 1014-1019.

15. Stitt TN, Drujan D, Clarke BA, et al. (2004) The IGF-1/PI3K/ Akt pathway prevents expression of muscle atrophy-induced ubiquitin ligases by inhibiting FOXO transcription factors. Mol Cell 14, 395-403. 
16. Latres E, Amini AR, Amini AA, et al. (2005) Insulin-like growth factor-1 (IGF-1) inversely regulates atrophy-induced genes via the phosphatidylinositol 3-kinase/Akt/mammalian target of rapamycin (PI3K/Akt/mTOR) pathway. J Biol Chem 280, 2737-2744.

17. Burgering BMT (2008) A brief introduction to FOXOlogy. Oncogene 27, 2258-2262.

18. Tesseraud S, Bouvarel I, Collin A, et al. (2009) Daily variations in dietary lysine content alter the expression of genes related to proteolysis in chicken pectoralis major muscle. J Nutr 139, 38-43.

19. Bradford MM (1976) A rapid and sensitive method for the quantitation of microgram quantities of protein utilizing the principle of protein-dye binding. Anal Biochem 72, $248-254$

20. Wen C, Wang LC, Zhou YM, et al. (2012) Effect of enzyme preparation on egg production, nutrient retention, digestive enzyme activities and pancreatic enzyme messenger RNA expression of late-phase laying hens. Anim Feed Sci Technol 172, 180-186.

21. Vandesompele J, De Preter K, Pattyn F, et al. (2002) Accurate normalization of real-time quantitative RT-PCR data by geometric averaging of multiple internal control genes. Genome Biol 3, 0034.1-0034.11.

22. Li Y, Yuan L, Yang X, et al. (2007) Effect of early feed restriction on myofibre types and expression of growth-related genes in the gastrocnemius muscle of crossbred broiler chickens. Br J Nutr 98, 310-319.

23. Kogut $\mathrm{MH}$, Iqbal $\mathrm{M}$, He $\mathrm{H}$, et al. (2005) Expression and function of Toll-like receptors in chicken heterophils. Dev Comp Immunol 29, 791-807.

24. Wang XQ, Jiang W, Tan HZ, et al. (2013) Effects of breed and dietary nutrient density on the growth performance, blood metabolite, and genes expression of target of rapamycin (TOR) signalling pathway of female broiler chickens. J Anim Physiol Anim Nutr 97, 797-806.
25. Pfaffl MW (2001) A new mathematical model for relative quantification in real-time RT-PCR. Nucleic Acids Res 29, e45.

26. Guernec A, Berri C, Chevalier B, et al. (2003) Muscle development, insulin-like growth factor-I and myostatin mRNA levels in chickens selected for increased breast muscle yield. Growth Horm IGF Res 13, 8-18.

27. Ahmed ME \& Abbas TE (2011) Effects of dietary levels of methionine on broiler performance and carcass characteristics. Int J Poult Sci 10, 147-151.

28. Carew L, McMurtry J \& Alster F (2003) Effects of methionine deficiencies on plasma levels of thyroid hormones, insulinlike growth factors-I and -II, liver and body weights, and feed intake in growing chickens. Poult Sci 82, 1932-1938.

29. Nagao K, Oki M, Tsukada A, et al. (2011) Alleviation of body weight loss by dietary methionine is independent of insulinlike growth factor-I in protein-starved young chickens. Anim Sci J 82, 560-564.

30. Guernec A, Chevalier B \& Duclos MJ (2004) Nutrient supply enhances both IGF-I and MSTN mRNA levels in chicken skeletal muscle. Domest Anim Endocrinol 26, 143-154.

31. Foletta V, White L, Larsen A, et al. (2011) The role and regulation of MAFbx/atrogin-1 and MuRF1 in skeletal muscle atrophy. Pflugers Arch 461, 325-335.

32. Tesseraud S, Métayer-Coustard S, Boussaid S, et al. (2007) Insulin and amino acid availability regulate atrogin- 1 in avian QT6 cells. Biochem Biophys Res Commun 357, 181-186.

33. Nakashima K, Yakabe Y, Yamazaki M, et al. (2006) Effects of fasting and refeeding on expression of atrogin-1 and Akt/ FOXO signaling pathway in skeletal muscle of chicks. Biosci Biotechnol Biochem 70, 2775-2778.

34. Luo J, Chen D \& Yu B (2010) Effects of different dietary protein sources on expression of genes related to protein metabolism in growing rats. Br J Nutr 104, 1421-1428.

35. Moylan JS, Smith JD, Chambers MA, et al. (2008) TNF induction of atrogin-1/MAFbx mRNA depends on Foxo4 expression but not AKT-Foxo1/3 signaling. Am J Physiol Cell Physiol 295, C986-C993. 